\title{
CONTROLE BIOLÓGICO DE NEMATÓIDES EM ALFACE COM Bacillus subtilis
}

Sandy Breschi Segato, Daniele Perreti Bettio, Viviane Cacefo, Fabio Fernando de Araujo.

Universidade do Oeste Paulista - UNOESTE; Mestrado em Agronomia - Programa de Pós Graduação, Presidente Prudente,SP. E-mail: sandysegato@hotmail.com

\section{RESUMO}

O presente trabalho teve como objetivo avaliar o desenvolvimento do alface e controle de nematóides após serem introduzidas doses crescentes de Bacillus subtilis ao substrato, onde posteriormente a hortaliça foi transplantada em solo infestado com nematóides do gênero Meloidogyne. $O$ experimento foi conduzido em estufa localizada na Unoeste - Presidente Prudente - SP. O substrato recebeu doses crescentes de Bacillus subtilis formulado em pó: 0,0\%, 0,5\%, 1,0\%, $2,0 \%$ e $4,0 \%$ correspondentes a $0,0 \mathrm{~g}, 5,0 \mathrm{~g}, 10,0 \mathrm{~g}, 20,0 \mathrm{~g}$ e $40,0 \mathrm{~g}$. Foi utilizada a cultivar de alface Vanda. Avaliou-se comprimento de raiz e massa fresca da parte aérea de 20 mudas após 32 dias, sendo que 10 mudas foram transplantadas para o solo infestado com nematóides. $O$ uso de Bacillus subtilis foi eficiente no controle do nematóide Meloidogyne spp. A dose de $4,0 \%$ aplicada ao substrato melhorou o desenvolvimento das plantas de alface.

Palavras-chave: Rizobactérias. Meloidogyne. Lactuva sativa. Hortaliças. Substrato.

\section{CONTROL BIOLOGICAL OF NEMATODES IN LETTUCE WITH Bacillus subtilis}

\begin{abstract}
This study aimed to evaluate the development of lettuce and control of nematodes after being introduced increasing doses of Bacillus subtilis the substrate where later the vegetable was transplanted into soil infested with nematodes of the genus Meloidogyne. The experiment was conducted in a greenhouse located in Unoeste - Presidente Prudente - SP. The substrate received increasing doses of Bacillus subtilis powder: $0.0 \%, 0.5 \%, 1.0 \%, 2.0 \%$ and $4.0 \%$ corresponding to $0,0 \mathrm{~g}, 5.0 \mathrm{~g}, 10.0 \mathrm{~g}, 20,0 \mathrm{~g}$ and $40,0 \mathrm{~g}$. It was used to grow lettuce Vanda. We evaluated the length of root and shoot fresh weight of 20 seedlings after 32 days, and 10 seedlings were transplanted into soil infested with nematodes. The use of Bacillus subtilis was efficient in the control of Meloidogyne spp. The dose of $4.0 \%$ applied to the substrate improved the development of lettuce plants.
\end{abstract}

Keywords: Rhizobacteria Meloidogyne. Lactuca sativa. Vegetables. Substrate. 


\section{INTRODUÇÃO}

O alface (Lactuca sativa) está entre as hortaliças folhosas mais consumidas no País (KIEHL, 1985; SMITH; HADLEY, 1989). Entretanto há uma preocupação quanto ao cultivo de hortaliças no que se refere à sanidade do solo, pois geralmente são suscetíveis à infestações de nematóides, dentre os gêneros que mais atacam esses vegetais podemos citar nematoide de galha (Meloidogyne), se destacando $M$. incognitae $M$. javanica, ambos possuem capacidade de reprodução em diversos solos e temperaturas, aumentando sua incidência nas regiões produtoras (PINHEIRO et al., 2010).

Os prejuízos ocasionados pelos nematóides de galha nas plantas são severos, pois causam apodrecimento nas raízes, servindo de entrada para outros patógenos (PINHEIRO et al., 2010). De tal forma, existem sintomas visíveis nas raízes, caracterizados pelo tamanho, isto é, as raízes não se desenvolvem e apresentam poucas raízes laterais, além de apresentarem inchaços em formatos arredondados. Nas folhas há aparência amarelada, o comprimento da parte aérea é reduzido e o seu peso mais leve, as folhas ficam fáceis de serem desprendidas por estarem fracas e murchas (PEREIRA et al., 2013).

Atualmente adotou-se o uso de rizobactérias promotoras de crescimento em plantas (RPCPS), por aumentarem o desenvolvimento vegetal, e serem eficientes em controle biológico de nematóides. As RPCPS agem principalmente na redução de eclosão dos ovos de nematóides, pois alteram os exsudatos radiculares dificultando o acesso as raízes por parte dos nematóides. Dentre as RPCPS podemos citar o Bacillus, (VAZ et al., 2011) onde existem relatos de ação antagônica para com o Meloidogyne (ARAUJO et al., 2012) interferido em seu ciclo reprodutivo, aumentando a biomassa da parte aérea das plantas e reduzindo a formação de galhas nas raízes (ARAUJO; MARCHESI, 2009).

A partir do tratamento biológico sobre a reprodução de nematóides, se destaca a redução deles na fase juvenil e na massa de ovos nas raízes (ARAUJO; MARCHESI, 2009) e dentre os outros benefícios ocasionados pelo Bacillus subtilis está a maior fixação de nitrogênio, solubilização dos nutrientes e síntese de fitormônios, aumento o crescimento das plantas (FILHO et al., 2010).

Portanto, o objetivo do presente trabalho foi avaliar o desenvolvimento de alface, e o controle de nematóides em plantas previamente inoculadas com doses crescentes de Bacillus subtilis ao substrato, cultivadas posteriormente ao transplante em solo infestado com nematóides do gênero Meloidogyne.

\section{METODOLOGIA}

O experimento foi conduzido em estufa de produções de mudas, no Campus II da UNOESTE no município de Presidente Prudente - SP, com coordenadas geográficas 51 26'00" de longitude Oeste de Greenwich e 22ㅇ 07'30" de latitude Sul, com altitude de 433 metros. O clima da região é pela classificação de KöppenAw como mesotérmico com verões quentes e período chuvoso bem definido nos meses de setembro a março e invernos secos com temperaturas mais amenas nos meses de abril a setembro.

No inicio do experimento bandejas de 200 células de poliestireno expandido foram preenchidas com substrato comercial da marca Bioplant. Foram posteriormente preparadas porções de $1,0 \mathrm{~kg}$ do substrato as quais receberam a aplicação de Bacillus subtilis, nas dosagens de 0,$0 ; 0,5 ; 1,0 ; 2,0 ; 4,0 \%$, correspondentes a 0,$0 ; 5,0 ; 10,0 ; 20,0$ e 40,0 gramas. Após o preenchimento das bandejas foram semeadas uma semente de Alface (cultivar Vanda) células ${ }^{1} \mathrm{e}$ dispostas na estufa. O delineamento experimental adotado foi em blocos ao acaso com vinte repetições.

As mudas foram mantidas por 32 dias em estufa, recebendo irrigação periódica. Após este período foram retiradas vinte mudas aleatoriamente de cada tratamento para as análises de 
comprimento e massa fresca do sistema radicular e parte aérea. Para a análise da massa fresca, as mudas foram retiradas da bandeja, fracionadas em parte aérea, e sistema radicular, lavadas em água corrente para a remoção do substrato e pesadas em balança analítica para o comprimento de raiz e parte aérea fez-se uso de uma régua.

Foi realizado o transplante aos 32 dias de 10 mudas de cada tratamento para sacos plásticos contendo $2 \mathrm{~kg}$ de solo, sendo este solo infestado naturalmente por nematóides do gênero Meloidogyne. Destaca-se que a população inicial do solo (no momento da coleta) foi de 120 nematóides $100 \mathrm{~g}^{-1}$ de solo, quantificada a partir da técnica de Jenkins (1964).

As mudas transplantadas foram mantidas em estufa por 30 dias, recebendo irrigação periódica, sendo retirada após este período, fracionada em parte aérea e sistema radicular, lavadas para a remoção do substrato, encaminhadas à balança de precisão para determinação da massa fresca de parte aérea e sistema radicular. Em seguida, o sistema radicular foi destinado à extração dos nematóides das raízes, pela técnica de Coolen et al, (1972), efetuada imediatamente após as coletas. A contagem foi realizada com auxílio da câmara de Peters, no microscópio óptico, para quantificação de nematóides do gênero Meloidogyne.

Os dados obtidos foram submetidos à análise de variância pelo Teste de Tukey utilizando o programa SISVAR e posteriormente se realizou análise de regressão para avaliar as doses de Bacillus subtilis aplicadas aos referentes tratamentos.

\section{RESULTADOS}

De acordo com a tabela 1, o crescimento das mudas na bandeja apresentaram diferenças significativas em todos os parâmetros avaliados, com destaque para o desempenho do tratamento com a aplicação na dose de 4,0 \% da rizobactéria.

Tabela 01. Médias de comprimento e massa fresca de sistema radicular e parte aérea de mudas de alface após 32 dias em função de diferentes doses de $B$. subtilis aplicados no substrato.

\begin{tabular}{|c|c|c|c|c|}
\hline \multirow{2}{*}{ Tratamentos } & \multicolumn{2}{|c|}{ Comprimento $(\mathrm{cm})$} & \multicolumn{2}{|c|}{ Massa Fresca (g) } \\
\hline & Raiz & Parte aérea & Raiz & Parte aérea \\
\hline $0,0 \%$ & $5,73 \mathrm{~b}$ & $0,17 \mathrm{~d}$ & $5,12 \mathrm{~d}$ & $0,42 d$ \\
\hline $0,5 \%$ & $6,85 \mathrm{a}$ & $0,22 \mathrm{c}$ & $5,62 \mathrm{~cd}$ & $0,47 \mathrm{~cd}$ \\
\hline $1,0 \%$ & $6,47 a$ & $0,23 \mathrm{c}$ & $5,77 \mathrm{c}$ & $0,49 \mathrm{c}$ \\
\hline $2,0 \%$ & $6,26 a b$ & $0,29 \mathrm{~b}$ & $7,17 \mathrm{~b}$ & 0,69 a \\
\hline $4,0 \%$ & $6,47 a$ & $0,34 a$ & 8,81 a & $1,07 a$ \\
\hline Teste F & $7,20 *$ & $109,85^{* *}$ & $45,31 *$ & $427,48^{* *}$ \\
\hline CV (\%) & 10,67 & 16,83 & 9,83 & 9,21 \\
\hline
\end{tabular}

O ajuste da curva exponencial (Figura 1) indica que o aumento da massa fresca e do sistema radicular em resposta as doses de Bacillus subtilis pode ser positiva e crescente. Isto pode indicar a viabilidade do uso de doses maiores da bactéria no substrato. 


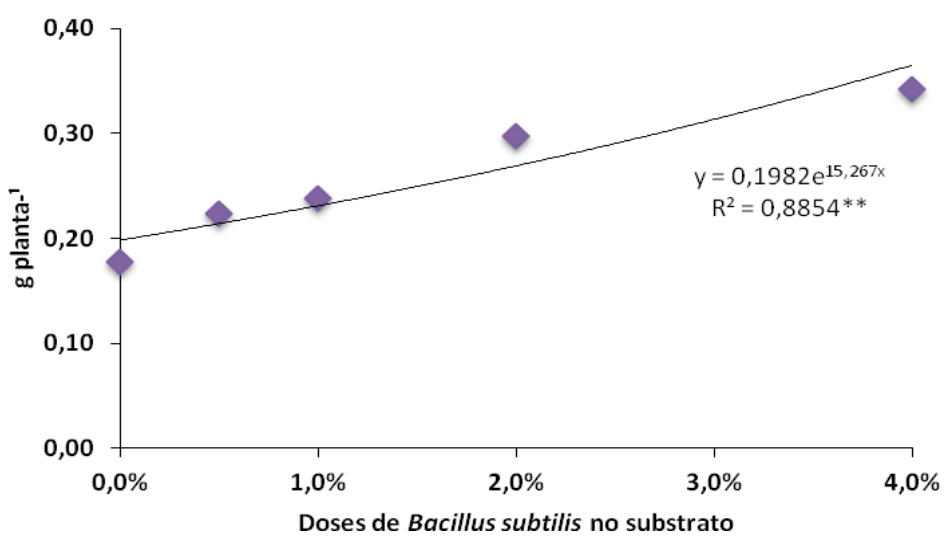

Figura 01. - Massa fresca do sistema radicular de alface em função de doses crescentes de Bacillus subtilis

Ocorreu um ajuste da curva na análise de regressão no comprimento da parte aérea e na massa fresca das plantas (Figura 2 e 3) mostrando que ambos os parâmetros avaliados foram maiores conforme se aumentou a dose de Bacillus subtilis no substrato.
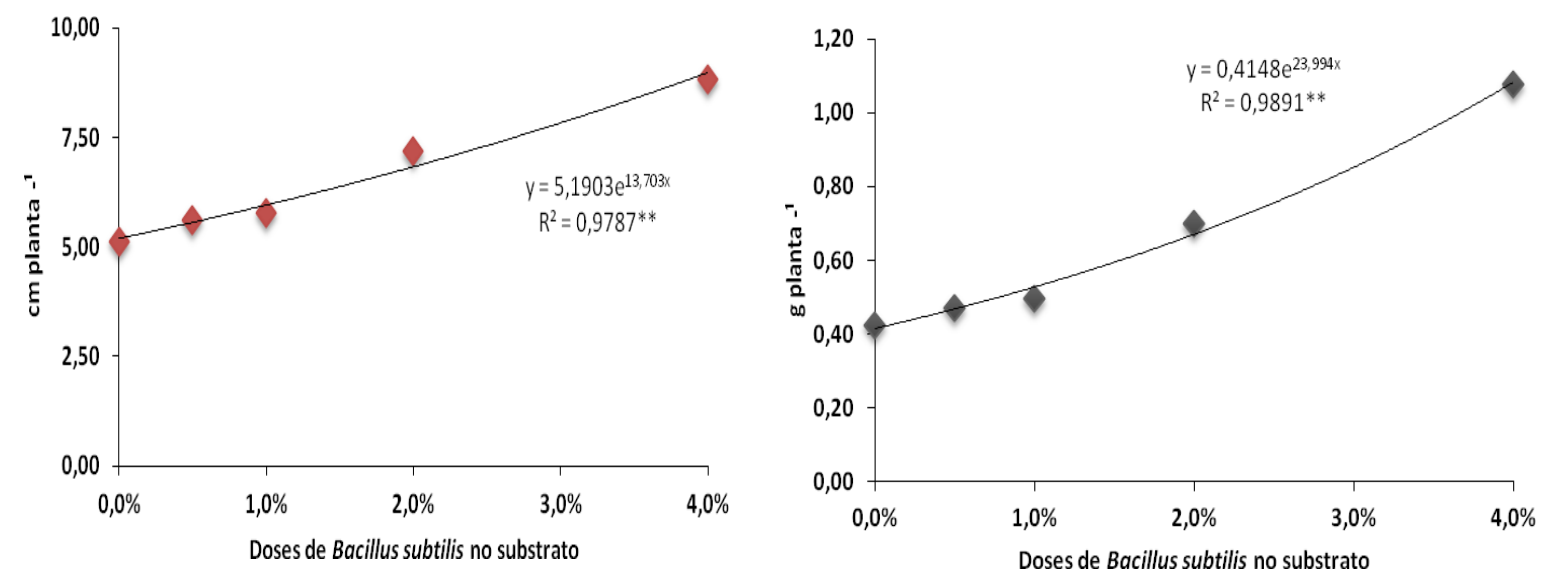

Figura 02 e 03. Comprimento e Massa Fresca da parte aérea do alface em função de doses crescentes de Bacillus subtilis.

Nas plantas cultivadas em solo infestado com nematóides, observou-se resposta das plantas às doses da bactéria (Tabela 2). A dose de 4,0\% proporcionou maiores incrementos em comprimento de parte aérea comparada ao controle $(0,0 \%)$ e ao tratamento de $0,5 \%$ da dose da bactéria. 
Tabela 02. Médias de comprimento e massa fresca de sistema radicular e parte aérea de alface com 30 dias em função de diferentes doses de $B$. subtilis aplicados no substrato.

\begin{tabular}{ccccc}
\hline \multirow{2}{*}{ Tratamentos } & \multicolumn{2}{c}{ Comprimento $(\mathrm{cm})$} & \multicolumn{2}{c}{ Massa Fresca $(\mathrm{g})$} \\
\cline { 2 - 5 } & Raiz & Parte aérea & Raiz & Parte aérea \\
\hline $0,0 \%$ & 6,35 & $23,75 \mathrm{~b}$ & 1,40 & 51,85 \\
$0,5 \%$ & 6,50 & $23,25 \mathrm{~b}$ & 1,42 & 42,56 \\
$1,0 \%$ & 6,60 & $26,00 \mathrm{ab}$ & 1,40 & 43,44 \\
$2,0 \%$ & 6,70 & $26,10 \mathrm{ab}$ & 1,42 & 42,65 \\
$4,0 \%$ & 7,55 & $29,00 \mathrm{a}$ & 1,59 & 58,28 \\
\hline Teste F & $0,37 \mathrm{~ns}$ & $4,65^{*}$ & $0,71 \mathrm{~ns}$ & $1,72 \mathrm{~ns}$ \\
\hline CV (\%) & 36,09 & 13,28 & 14,19 & 35,57
\end{tabular}

NS Não significativo ao Teste $\mathrm{F}$ com nível de $5 \%$ de probabilidade.

* Significativo ao Teste F com nível de $5 \%$ de probabilidade.

Médias seguidas da mesma letra nas colunas não diferem entre si pelo teste de Tukey

Ao observar os nematoides no sistema radicular das plantas cultivadas no solo infestado, observou-se que apenas a dose de $2 \%$ afetou significativamente as larvas e os ovos.

Tabela 03. Médias de larvas e ovos de Meloidogyne spp. no sistema radicular de alface com 32 dias em função de diferentes doses de $B$. subtilis aplicados no substrato.

\begin{tabular}{ccc}
\hline \multirow{2}{*}{ Tratamentos } & \multicolumn{2}{c}{ Sistema radicular } \\
\cline { 2 - 3 } & Larvas (no raiz- ${ }^{1}$ de planta) & Ovos (no raiz- ${ }^{1}$ de planta) \\
\hline $0,0 \%$ & $748,00 \mathrm{~b}$ & 263,33 \\
$0,5 \%$ & $488,00 \mathrm{ab}$ & 159,50 \\
$1,0 \%$ & $563,00 \mathrm{ab}$ & 74,00 \\
$2,0 \%$ & $99,00 \mathrm{a}$ & 40,00 \\
$4,0 \%$ & $182,00 \mathrm{a}$ & 173,00
\end{tabular}

\begin{tabular}{ccc}
\hline Teste $\mathrm{F}$ & $5,45^{*}$ & $2,30 \mathrm{~ns}$ \\
\hline $\mathrm{CV}(\%)$ & 41,36 & 70,76
\end{tabular}

* e ** Significativos ao Teste $\mathrm{F}$ com nível de $5 \%$ e $1 \%$ de probabilidade, respectivamente. Médias seguidas da mesma letra nas colunas não diferem entre si pelo teste de Tukey. 


\section{DISCUSSÃO}

Os crescimentos das mudas e das plantas cultivadas em solo infestado de nematoides tiveram resposta significativa à dose de $4,0 \%$ da rizobactéria. Observando que conforme 0 aumento das doses, maiores as respostas de aumento de parte aérea e raiz.

No feijão, o uso de Bacillus spp. foi promissor quanto à nodulação de raízes e crescimento de plantas (LAZZARETTI;MELO,2005), e no tomate aumento de biomassa da parte aérea (ARAÚJO; MARCHESI, 2009). Ao combinar fungo micorrízico Glomus sp. com a bactéria Pasteuria penetrans, Talavera et al, (2002) observaram que houve maiores benefícios do que quando se utilizou um único organismo, proporcionando redução na densidade dos juvenis de $M$. incognita em 57 e $61 \%$, em cultivares de tomate, além de maiores incrementos no crescimento das plantas e na produção de frutos.

A dose de $2 \%$ da rizobactéria foi significativa na redução de larvas e ovos se comparado aos outros tratamentos e a testemunha. Até o presente trabalho não foi encontrado pesquisas que afirmem a eficácia de doses menores ou maiores de $2,0 \%$ no controle de larvas e ovos de nematoide.

Vaz et al. (2011) na microbiolização de sementes com isolados de Bacillus spp. para o controle de 2 tipos de Meloidogyne, não teve redução na formação de galhas e ovos.

Semelhante a este trabalho, Fernandes et al. (2013) Avaliou o controle de Meloidogyne javanica em feijoeiro com isolados de Bacillus spp., não tendo diminuição significativa de galhas e ovos, porém o isolado 51 reduziu a produção de ovos de nematoides em 4 vezes comparado a testemunha.

Araujo et al. (2002) demonstram reduções de cistos de nematoides em soja, se adicionado Bacillus subtilis diretamente no solo. Os mesmos autores afirmam que as interferências podem estar relacionadas a fatores químicos ou metabólicos dos microrganismos.

As altas colonizações radiculares das plantas pelas RPCPS inibem parasitas através da antibiose, pela produção de compostos tóxicos, diminuindo a eclosão e aumentando a mortalidade larval de nematoides; ainda são capazes de aumentar a produção de enzimas relacionadas à patogênese, além de aumentar a fixação de nitrogênio favorecendo o crescimento vegetal (LUDWIG, 2009).

\section{CONCLUSÃO}

A dose de $4 \%$ de Bacillus subtilis proporcionou maior rendimento aéreo e radicular na alface. O Bacillus subtilis se mostrou eficiente no controle larval do nematóide, sendo que a dose de $2 \%$ de Bacillus subtilis diminuiu em até $87 \%$ as larvas de nematóides nas raízes das plantas de alface com relação ao tratamento controle.

\section{REFERENCIAS}

ARAUJO FF; SILVA JFV; ARAUJO ASF; Influência de Bacillus subtilis na eclosão, orientação e infecção de Heterodera glycines em soja. Ciência Rural, Santa Maria, v.32, n. 2, p.197-202, 2002. https://doi.org/10.1590/S0103-84782002000200003

ARAUJO FF; BRAGANTE RJ; BRAGANTE CE; Controle genético, químico e biológico de Meloidogyne na cultura da soja. Pesquisa Agropec. V.42, n.2, p.220-224, 2012. https://doi.org/10.1590/S1983$\underline{40632012000200013}$

ARAUJO FF; MARCHESI GVP; Uso de Bacillussubtilis no controle de meloidoginose e na promoção do crescimento do tomateiro. Ciência Rural, Santa Maria, v.39, n,5 p.1558-1561, Ago, 2009. 
COOLEN, W. A. et al. A method for the quantitative extraction of nematodes from plant tissue. Ghent, 1972.

FERNANDES RH; LOPES EA; VIEIRA BS; BONTEMPO AF; Controle de Meloidogyne javanica na cultura do Feijoeiro com isolados de Bacillus spp. Revista Tropica: Ciências Agrárias e Biologicas, v. 7, n.1- 2013.

FILHO RL; FERRO MH; PINHO RSC; Controle Biológico Mediado por Bacillussubtilis. Revista Trópica - Ciências Agrárias e Biológicas V.4 N2 p.12 - p.20, 2010.

JENKINS, WRb et al. A rapid centrifugal-flotation technique for separating nematodes from soil. Plant disease reporter, v. 48, n. 9, 1964.

KIEHL, E. J. Fertilizantes orgânicos. Piracicaba: Agronômica Ceres, 1985. 492 p.

LAZZARETTI, E.; MELO I.S.M.; Influência de Bacillus subtilis na promoção de crescimento de plantas e nodulação de raízes de feijoeiro. Jaguariúna, EMBRAPA Boletim de pesquisa e desenvolvimento no 28, 2005.

LUDWIG, J. Potencial de isolados bacterianos como biocontroladores de nematoides e fungos e como indutores de resistência em plantas de arroz. 2009. 104p. Tese (Doutorado) - Universidade Federal de Pelotas, Pelotas.

PEREIRA RB; PINHEIRO JB; CARVALHO ADF; Diagnose e controle de doenças em alface, alho, cebola e brássicas. Brasília, EMBRAPA Circular técnica n. 120, p. 12-16, 2013.

PINHEIRO JB; AMARO GB; PEREIRA RB; Ocorrência e controle de nematóides em hortaliças folhosas. EMBRAPA Circular técnica, vol. 89, Brasília, Nov. 2010.

SMITH, S. R.; HADLEY, P. A comparison of the effects of organic and inorganic nitrogen fertilizers on the growth response of summer cabbage (Brassica oleracea var. capitata cv. Hispe F1). Journal of Horticultural Science, Ashford, v.63, n. 4, p.615-620, 1988. https://doi.org/10.1080/14620316.1988.11515901

SOUZA JÚNIOR, I. T. et al. Biocontrole da queima das bainhas e do nematoide das galhas e promoção de crescimento de plantas de arroz por rizobactérias. Pesquisa Agropecuária Brasileira, v. 45, n. 11, p. 1259-1267, 2010. https://doi.org/10.1590/S0100-204X2010001100005

TALAVERA, M.; ITOU, K.; MIZUKUBO, T. Combined application of Glomus sp. and Pasteuria penetrans for reducing Meloidogyne incognita (Tylenchida: Meloidogynidae) populations and improving tomato growth. Applied Entomology and Zoology, v.37, p.61-67, 2002. https://doi.org/10.1303/aez.2002.61

VAZ MV; CANEDO EJ; MACHADO JC; VIEIRA BS; LOPES EA; Controle biológico de Meloidogynejavanica e Meloidogyne incógnita com Bacillus subtilis. Revista do núcleo interdisciplinar de pesquisa e extensão. Patos de Minas, UNIPAM, n.8, vol. 1, p. 203-212, jul.2011. 